\title{
Case Report \\ Surgical Treatment of a Chronically Recurring Case of Cervical Mucocele in a German Shepherd Dog
}

\author{
Davoud Kazemi, ${ }^{1}$ Yousef Doustar, ${ }^{2}$ and Gholamreza Assadnassab ${ }^{1}$ \\ ${ }^{1}$ Department of Veterinary Clinical Sciences, Faculty of Veterinary Medicine, Tabriz Branch, Islamic Azad University, Tabriz, Iran \\ ${ }^{2}$ Department of Veterinary Pathobiology, Faculty of Veterinary Medicine, Tabriz Branch, Islamic Azad University, Tabriz, Iran
}

Correspondence should be addressed to Davoud Kazemi, dkazemi@iaut.ac.ir

Received 10 January 2012; Accepted 19 February 2012

Academic Editors: R. M. Jerram and G. Stoica

Copyright ( 92012 Davoud Kazemi et al. This is an open access article distributed under the Creative Commons Attribution License, which permits unrestricted use, distribution, and reproduction in any medium, provided the original work is properly cited.

\begin{abstract}
A-six-year old male German shepherd dog with swelling and enlargement of the intermandibular and cervical region with a duration of nearly one year was referred to the small animal veterinary hospital, Islamic Azad University of Tabriz. Based on the history, clinical findings, and laboratory investigations, the animal was diagnosed as having cervical mucocele with the involvement of the left sublingual and mandibular salivary glands. Surgical treatment consisting of the excision of the involved gland/duct complex was immediately undertaken with definitive results. Clinical and histopathologic features of this chronic case of canine salivary mucocele are presented in this paper.
\end{abstract}

\section{Introduction}

A salivary mucocele or sialocele is an abnormal accumulation of saliva in the subcutaneous tissue adjacent to a damaged salivary gland or duct and is surrounded by granulation tissue. The saliva originates from a ruptured salivary gland or duct. The sublingual and mandibular salivary glands are most commonly affected [1-4]. In the present paper, an unusually large and chronic case of cervical mucocele is described in a German shepherd dog.

\section{Case Presentation}

A six-year-old male German shepherd dog was referred to the small animal veterinary hospital, Islamic Azad University of Tabriz with obvious swelling and enlargement of the cervical and intermandibular region. According to the dog's owner, the swelling had first appeared almost a year ago, and during this period the dog had no other abnormalities. The gradually enlarging swelling had been drained on several occasions by a private sector veterinarian during this time, and dilute povidone iodine solution had been injected into the swelling without clinical success.
On clinical examination, a very large fluctuant, nonpainful fluid filled mass was evident in the cervical and intermandibular region. Palpation of the mass caused drooling of saliva from the mouth. Body temperature, pulse, and respiration were within normal range and slight anemia, and increased neutrophil and band cells were detected on a complete blood count (CBC). Ultrasonographic evaluation revealed a hypoechoic region with a more echogenic border indicating a fluid filled cavity surrounded by a well-defined thick border. Based on the history and clinical findings, cervical mucocele was suspected. Aspiration of the mass under aseptic conditions was performed (Figure 1), and a thick mucoid, yellow blood tinged fluid which reacted positively with periodic acid schiff (PAS) stain (Figure 2) confirmed the presence of saliva and a diagnosis of mucocele. Because of the chronic nature of the disease, surgery was immediately undertaken to excise the involved gland and mass.

After premedication with acepromazine (Alfasan, Woerden, Holland), $0.05 \mathrm{mg} / \mathrm{kg}$ and atropine (Iran Pharmaceutical Development and Investment Co., Tehran, Iran), $0.02 \mathrm{mg} / \mathrm{kg}$, anesthesia was induced with $2.5 \%$ solution of thiopental (Sandoz GmbH, kundl, Austria) and maintained 


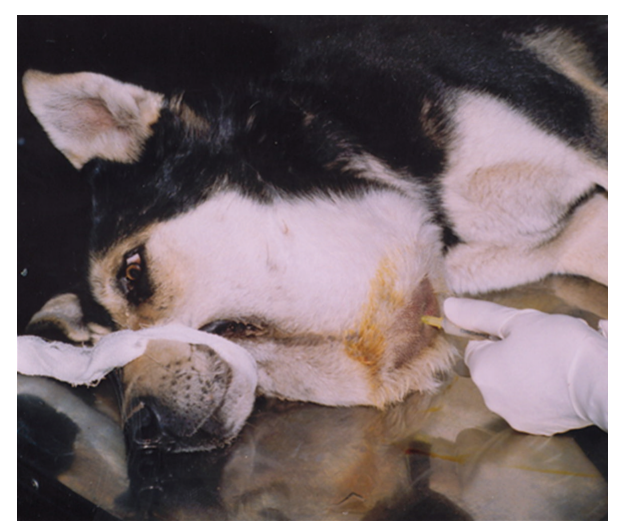

Figure 1: Aspiration of the cervical swelling under aseptic conditions. Note the extent and size of the swelling in the cervical and intermandibular region.

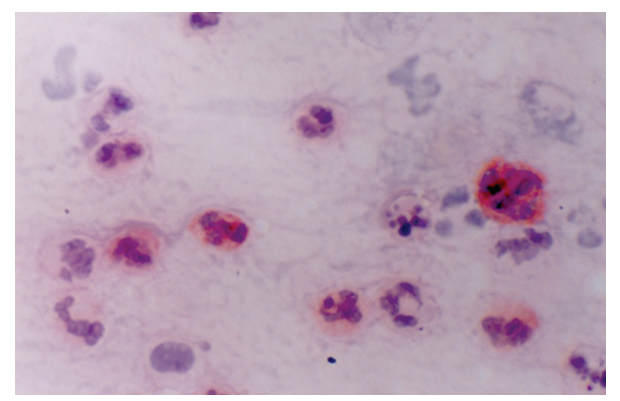

FIGURE 2: Periodic acid Schiff (PAS) staining of the aspirated fluid. The blue staining indicates that the fluid is saliva and confirms the diagnosis of mucocele. Note the presence of the inflammatory cells $(\times 400)$.

with halothane. The affected side was determined to be the left side by placing the animal in dorsal recumbency. The left mandibular and sublingual salivary glands were excised by making an incision over the mandibular gland region just caudal to the ramus of the mandible with the animal in right lateral recumbency (Figure 3(a)). After incising skin, subcutaneous tissues, and the platysma muscle, the capsule of the mandibular salivary gland was identified and incised to expose the gland. Dissection was continued rostrally to include the mandibular duct and closely associated sublingual gland. After complete removal, the incised muscular and subcutaneous tissues were sutured with absorbable sutures and the skin was routinely closed with nonabsorbable sutures. The mucocele was drained through a stab incision in the most ventrally dependant area, and approximately 1 litre of fluid was withdrawn. Due to cosmetic reasons, the large pendulous mass was also removed surgically (Figures $3(\mathrm{~b})$ and 3(c)). The animal recovered uneventfully and skin sutures were removed after 10 days.

On histopathologic examination, mild atrophy of the excised glands was observed (Figures 4(a) and 4(b)). The mucocele wall consisted of an outer highly vascularised layer of immature connective tissue and an inner zone of loosely arranged fibroblasts. A pleocellular inflammatory

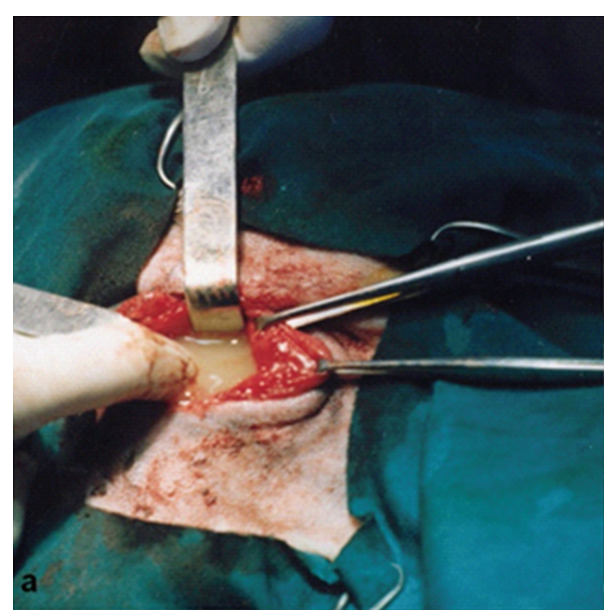

(a)

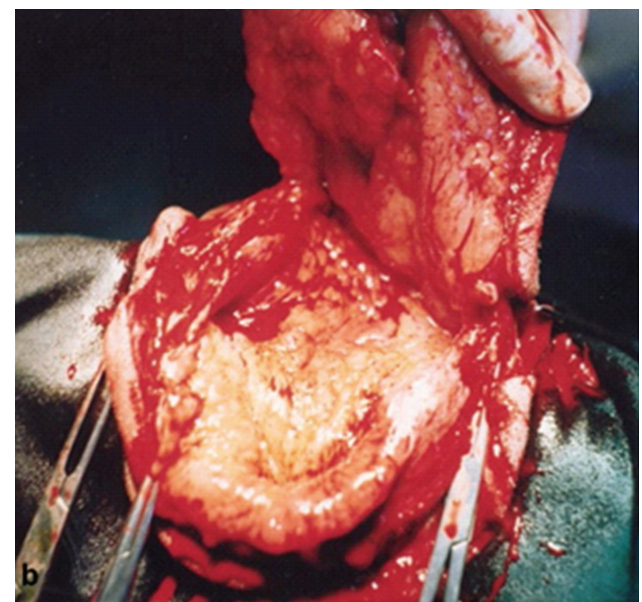

(b)

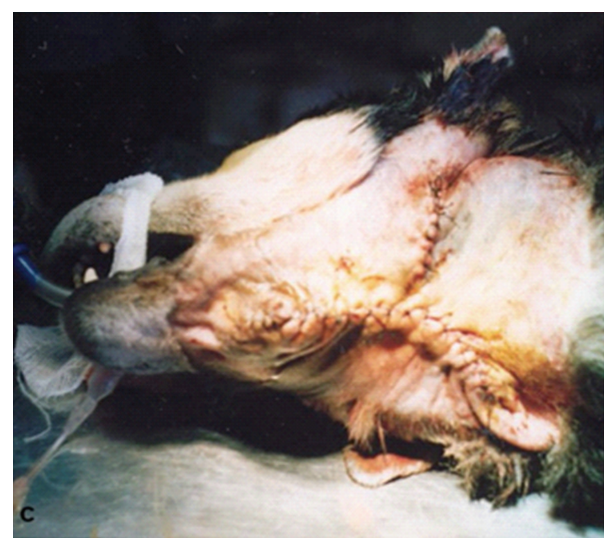

(c)

FIGURE 3: Intraoperative and postoperative views of the surgical procedure. Saliva was encountered at the incision site (a) and the surrounding reactive connective tissue is being excised (b). The cervical region resumes normality following the surgery (c).

reaction was evident in the central area, which also contained much amorphous acidophilic or amphophilic debris. The inflammatory cells were mainly mononuclear and plasma cells (Figures 4(c) and 4(d)). 


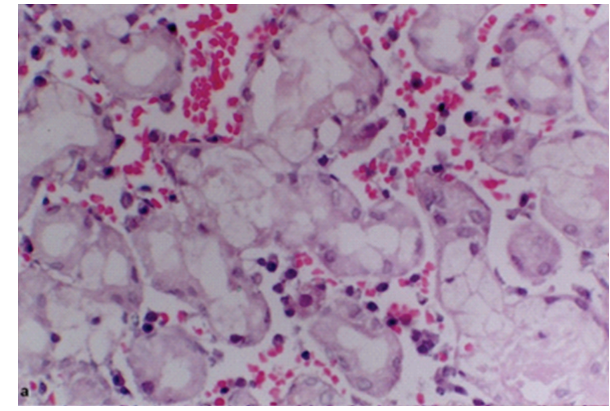

(a)

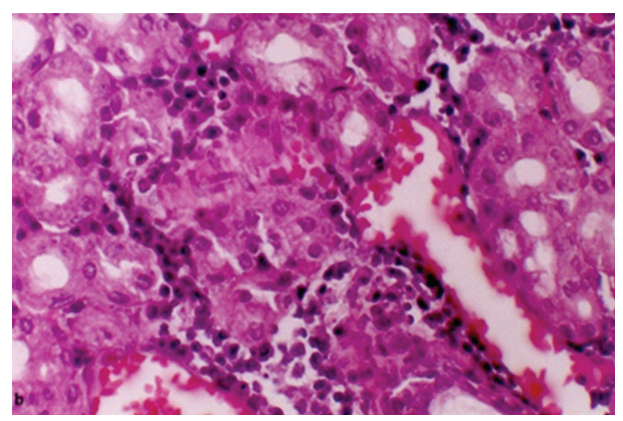

(b)

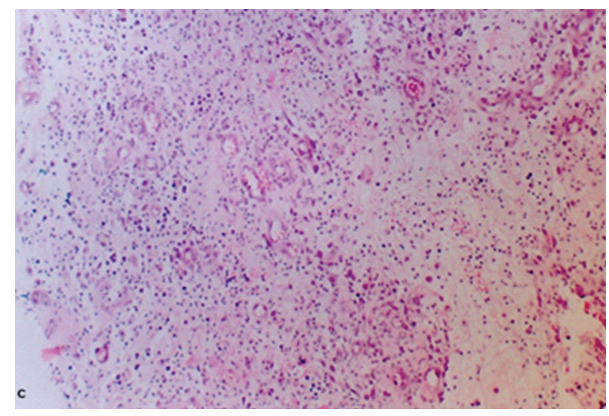

(c)

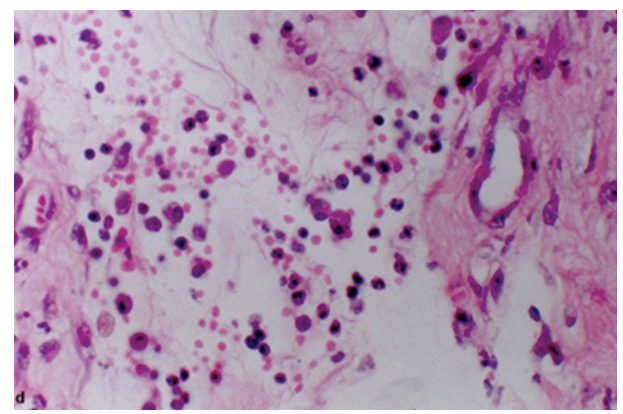

(d)

Figure 4: Histopathologic sections of the excised sublingual (a) and mandibular (b) salivary glands indicating mild atrophy and hemorrhage (Hematoxylin and Eosin, $\times 100$ ). The mucocele wall consisting of connective tissue lining and inflammatory cells is clearly evident (c) (Hematoxylin and Eosin, $\times 40$ ) alongside the presence of red blood cells and blood vessels (d) (Hematoxylin and Eosin, $\times 100)$.
The case was closely followed for a period of six months after the surgery, and there was no recurrence of the condition.

\section{Discussion}

Although diseases of the salivary glands are rare in small animals, mucocele is the most common clinically recognized disease of these structures in the dog, and the incidence of occurrence has been reported as fewer than 20 in 4000 dogs [5]. In most cases, the inciting cause of a salivary mucocele is usually unknown although blunt trauma, salivary gland or duct foreign bodies, sialoliths, and dirofilariasis have been suggested [1, 2, 5-7]. Clinically, a salivary mucocele is observed as an abnormal swelling containing saliva. The swelling is commonly observed in the cranial cervical or intermandibular, sublingual, or pharyngeal tissues hence cervical, sublingual, or pharyngeal mucoceles are used to describe these abnormal collections of saliva. A very rare form of this condition is the collection of saliva ventral to the globe known as zygomatic mucocele $[1-6,8]$. Dogs are more commonly affected than cats and although all breeds are susceptible, there are reports indicating that poodles, German shepherds, dachshunds, and Australian silky terriers are frequently affected [1-3]. The diagnosis of salivary mucocele is based on the history, clinical signs and histopathologic findings. Affected animals are presented with soft and fluctuant swellings which are painless except in the acute phase of the inflammatory response. Definitive treatment of this condition requires resection of the affected gland/duct complex. Repeated drainage or injection of cauterizing or anti-inflammatory agents will not only fail to eliminate the mucocele but will complicate the surgical procedure because of subsequent abscessation or fibrosis [1$3,8]$.

In the case described in this report, blunt trauma in the form of choke chain was the most probable inciting cause in this dog. The continuous pressure exerted by a very tight choke chain around the neck appeared to have damaged the sublingual and mandibular salivary gland/duct complex leading to gradually increasing accumulation of saliva manifested as cervical mucocele.

It has been observed that cervical mucocele is the most common form of this condition [9]. Previous studies have also pointed out that resection of the mandibular and sublingual salivary glands alongside drainage and excision of the redundant tissues is the most definitive treatment of this condition $[9,10]$ although in a high percentage of cases $(42 \%)$ drainage alone was employed for treatment of the affected animals which resulted in the recurrence of the condition within the next 48 hours [9]. This scenario was also observed in the present case, and, as stated by the dog's owner, the only form of treatment the animal had received before surgery consisted of drainage and injection of povidone iodine solution as a cauterizing agent which had merely complicated the situation. The basis for nonsurgical treatment of mucocele lies in the belief that mucocele is a true cyst with secretory lining but the fact that it is not a cyst but 
a reactive encapsulating structure has prompted the surgical removal of the affected salivary gland/duct complex with definitive results [5].

Sialography has been described as a method for the diagnosis of sialoceles [1-5], but it is technically difficult and in most cases like the present one it is unnecessary and, therefore, not often performed because the diagnosis can generally be accurately made by careful observation and palpation.

Salivary mucoceles are not cysts because they lack luminal epithelium and contain granulation tissue lining which originates from inflammatory reaction to free saliva $[7,11-$ 13]. It has been stated that the histopathologic appearance of salivary mucoceles varies according to their stage of development. In long standing cases, saliva is surrounded by mature dense connective tissue with abundant vessels, and the lumen of the sialocele contains eosinophilic amorphous material and desquamated cells indicating that the process of saliva secretion and mucocele formation is still continuous $[7,11]$. These features were also observed in the present case indicating the long standing and chronic nature of the condition in this particular animal.

\section{References}

[1] C. S. Hedlund and T. W. Fossum, "Surgery of the oral cavity and oropharynx," in Small Animal Surgery, T. W. Fossum, Ed., pp. 339-372, Mosby, St. Louis, Mo, USA, 3rd edition, 2007.

[2] D. Dunning, "Oral cavity," in Textbook of Small Animal Surgery, D. Slatter, Ed., pp. 553-572, Saunders, Philadelphia, Pa, USA, 3rd edition, 2003.

[3] C. D. Knecht, "Salivary glands," in Current Techniques in Small Animal Surgery, M. J. Bojrab, Ed., pp. 183-186, Williams \& Wilkins, Baltimore, Md, USA, 4th edition, 1998.

[4] K. M. Tobias, Manual of Small Animal Soft Tissue Surgery, Wiley-Blackwell, Ames, Iowa, USA, 2010.

[5] M. M. Smith, "Oral and salivary gland disorders," in Textbook of Veterinary Internal Medicine, S. J. Ettinger and E. C. Feldman, Eds., pp. 1290-1297, Elsevier, 6th edition, 2005.

[6] C. P. Sturgess, "Diseases of the alimentary tract," in Textbook of Small Animal Medicine, J. K. Dunn, Ed., pp. 371-447, W. B. Saunders, 2000.

[7] C. C. Brown, D. C. Baker, and I. K. Barker, "Alimentary system," in Jubb, Kennedy, and Palmer's Pathology of Domestic Animals, M. Grant Maxie, Ed., vol. 2, pp. 1-237, Elsevier, 2007.

[8] S. Manfra Marretta, "Dentistry and diseases of the oropharynx," in Saunders manual of Small Animal Practice, pp. 609635, Saunders, St. Louis, Mo, USA, 3rd edition, 2006.

[9] C. R. Bellenger and D. J. Simpson, "Canine sialocoeles-60 clinical cases," Journal of Small Animal Practice, vol. 33, no. 8, pp. 376-380, 1992.

[10] W. J. Weber, H. P. Hobson, and S. R. Wilson, "Pharyngeal mucoceles in dogs," Veterinary Surgery, vol. 15, no. 1, pp. 58, 1986.

[11] H. Yasonu, H. Nagai, Y. Ishimura et al., "salivary mucocele in a laboratory beagle," Journal of Toxicologic Pathology, vol. 24, pp. 131-135, 2011.

[12] H. J. van Kruiningen, "Gastrointestinal system," in Thomson's Special Veterinary Pathology, W. W. Carlton and M. D. McGavin, Eds., pp. 1-80, Mosby, St. Louis, Mo, USA, 2nd edition, 1995.
[13] H. B. Gelberg, "Alimentary system," in Pathologic Basis of Veterinary Disease, M. D. McGavin and J. F. Zachary, Eds., pp. 301-391, Mosby, 4th edition, 2007. 

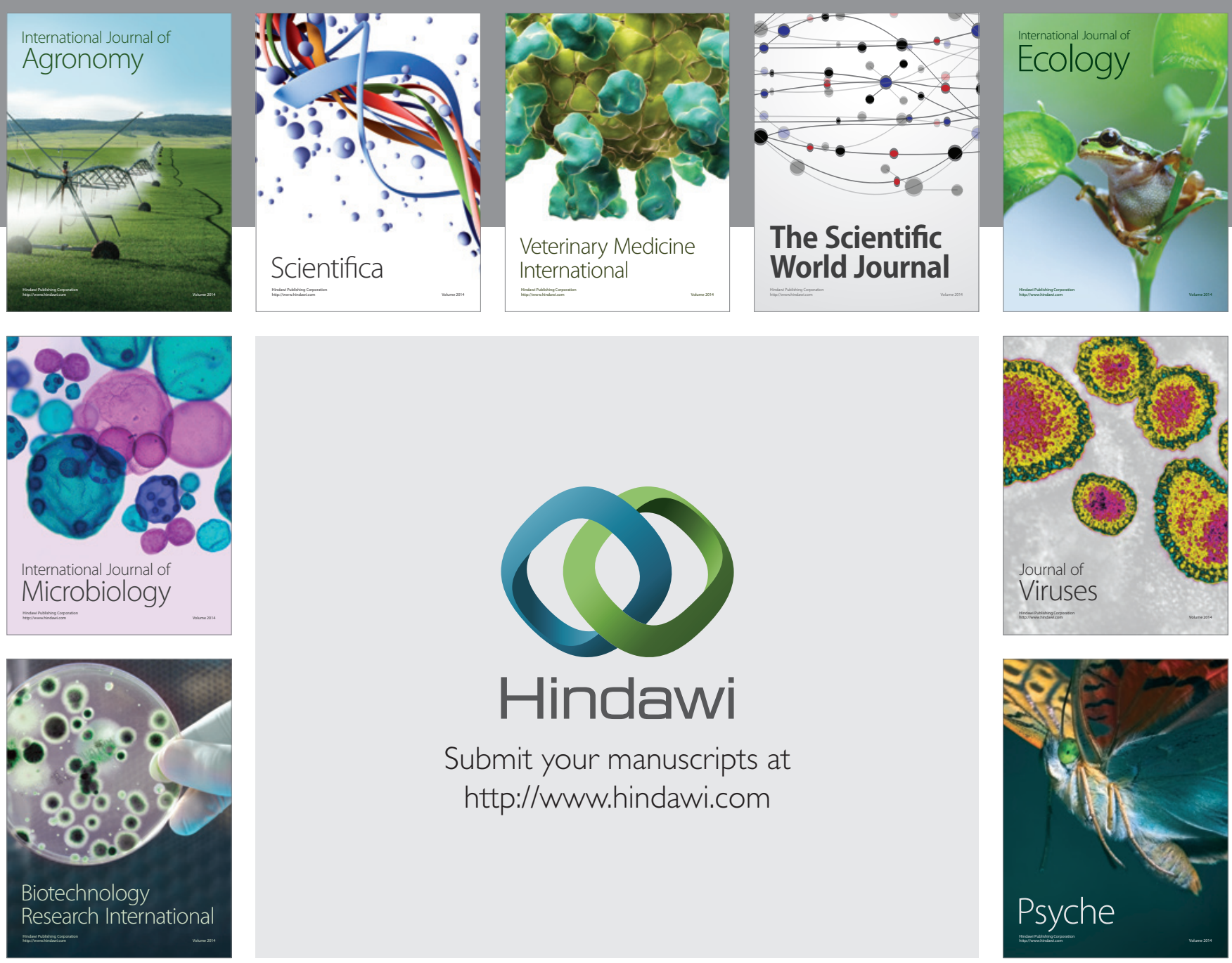

Submit your manuscripts at

http://www.hindawi.com
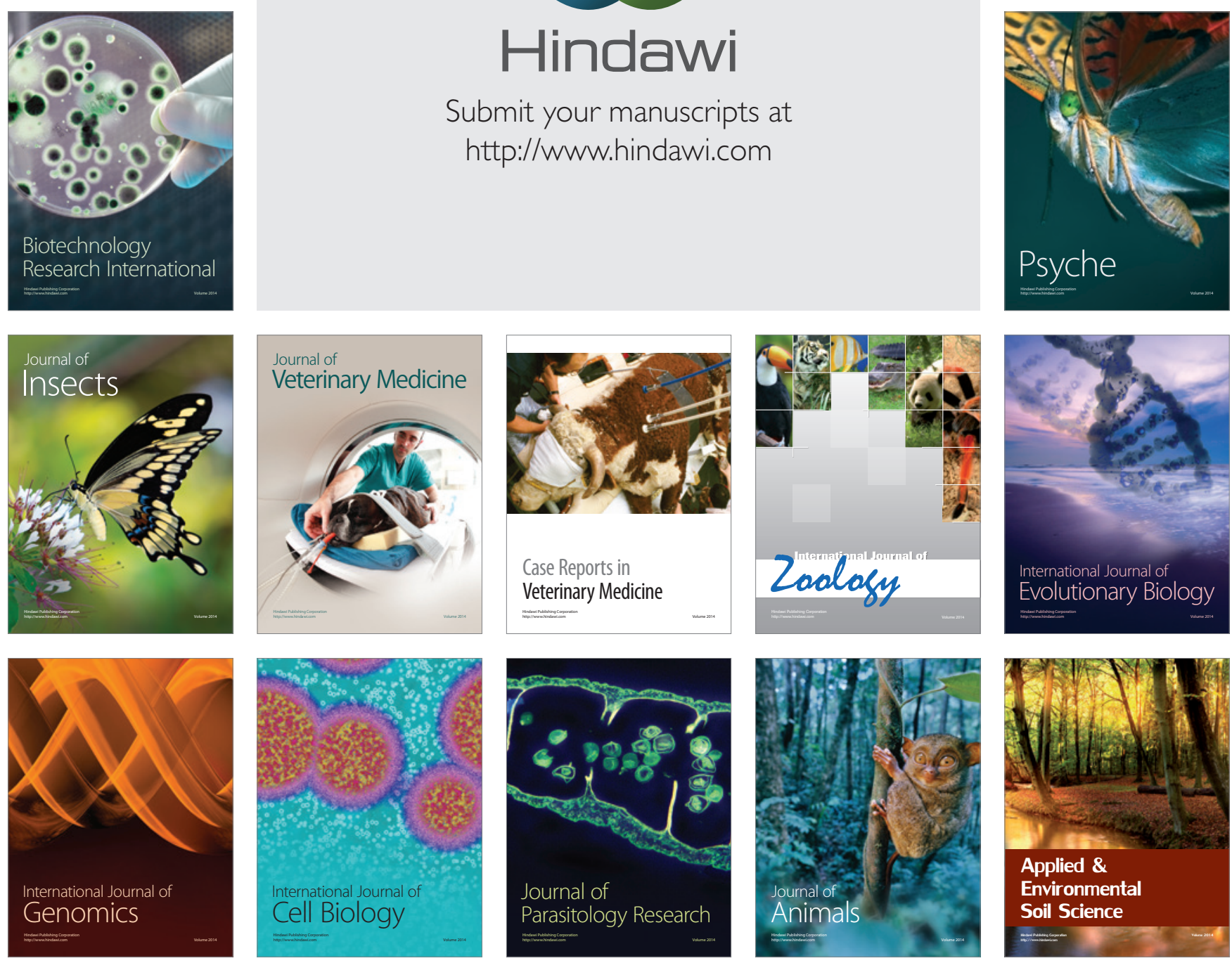